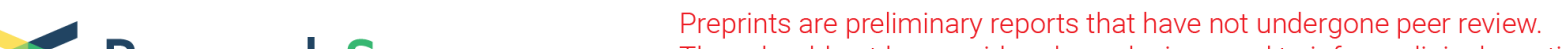 Research Square
or referenced by the media as validated information.
}

\section{Can The Function of The Tubarial Glands Be Evaluated Using 99mTc-pertechnetate SPECT/CT, 18F-FDG PET/CT, and 11C-Methionine PET/CT?}

Yohji Matsusaka ( $\square$ matsusaka.yohji@gmail.com )

Saitama Medical University International Medical Center https://orcid.org/0000-0003-3471-2762

\section{Tomohiko Yamane}

Saitama Medical University International Medical Center

\section{Kenji Fukushima}

Saitama Medical University International Medical Center: Saitama Ika Daigaku Kokusai Iryo Center

\section{Akira Seto}

Saitama Medical University International Medical Center

\section{Ichiro Matsunari}

Saitama Medical University International Medical Center

Ichiei Kuji

Saitama Medical University International Medical Center

\section{Research Article}

Keywords: tubarial gland, salivary gland, tonsil, 99mTc-pertechnetate, 18F-fluorodeoxyglucose, 11Cmethionine

Posted Date: March 18th, 2021

DOl: https://doi.org/10.21203/rs.3.rs-297940/v1

License: (9) This work is licensed under a Creative Commons Attribution 4.0 International License. Read Full License

Version of Record: A version of this preprint was published at EJNMMI Research on March 31st, 2021. See the published version at https://doi.org/10.1186/s13550-021-00779-6. 


\section{Abstract}

Background The tubarial glands (TGs) are recently reported as newly found salivary gland structures that can be organs at risk predominantly localized in the tori tubarius in the nasopharynx using prostatespecific membrane antigen positron emission tomography/computed tomography (PSMA PET/CT). The aims of this study were to analyze uptake in the TGs compared with that in the other salivary glands and palatine tonsils using ${ }^{99 \mathrm{~m}} \mathrm{Tc}$-pertechnetate SPECT/CT, ${ }^{18} \mathrm{~F}$-FDG PET/CT, and ${ }^{11} \mathrm{C}$-methionine PET/CT, and to confirm whether these three imaging modalities are useful in evaluating the physiological function of the TGs. Twelve and 130 patients, who underwent ${ }^{99 \mathrm{~m}} \mathrm{Tc}$-pertechnetate SPECT/CT and ${ }^{18} \mathrm{~F}-\mathrm{FDG} /{ }^{11} \mathrm{C}$ methionine PET/CT, respectively, were retrospectively included. ${ }^{99 \mathrm{~m}} \mathrm{Tc}$-pertechnetate uptake in the tori tubarius was visually assessed and semiquantitatively compared with that in the background, parotid salivary glands (PSGs), submandibular salivary glands (SmSGs), and sublingual salivary glands (SISGs). Correlations of ${ }^{18} \mathrm{~F}-\mathrm{FDG}$ and ${ }^{11} \mathrm{C}$-methionine uptakes in the tori tubarius with those in the other three salivary glands and palatine tonsils were analyzed.

Results ${ }^{99 \mathrm{~m}} \mathrm{Tc}$-pertechnetate uptake in the tori tubarius was invisible and was not significantly higher than that in the background. Both ${ }^{18} \mathrm{~F}-\mathrm{FDG}$ and ${ }^{11} \mathrm{C}$-methionine uptakes in the tori tubarius were correlated with that in the palatine tonsils $\left(r=0.56, p<0.0001 ; r=0.48, p<0.0001\right.$, respectively). ${ }^{18} \mathrm{~F}-\mathrm{FDG}$ uptake in the tori tubarius was not positively correlated with that in the PSGs, SmSGs, and SISGs $(r=-0.19, p=0.03 ; r$ $=-0.02, p=0.81 ; r=0.12, p=0.17$, respectively). ${ }^{11} \mathrm{C}$-methionine uptake in the tori tubarius was correlated with that in the SmSGs and SISGs $(r=0.24, p=0.01 ; r=0.32, p<0.01$, respectively), but not with that in the PSGs $(r=0.16, p=0.08)$.

Conclusions The TGs were undetectable on ${ }^{99 \mathrm{~m}} \mathrm{Tc}$-pertechnetate SPECT/CT. Both ${ }^{18} \mathrm{~F}$-FDG and ${ }^{11} \mathrm{C}$ methionine uptakes in the tori tubarius were clearly affected by that in the palatine tonsils and was little related to that in the other salivary glands. Therefore, it seems difficult to evaluate the physiological function of the TGs as salivary glands using ${ }^{99 \mathrm{~m}} \mathrm{TC}$-pertechnetate SPECT/CT, ${ }^{18} \mathrm{~F}-\mathrm{FDG}$ PET/CT, and ${ }^{11} \mathrm{C}$ methionine PET/CT imaging.

\section{Background}

The tubarial glands (TGs) are recently reported by Valstar et al. as newly found salivary gland structures that can be organs at risk localized in the posterior wall of the nasopharynx using prostate-specific membrane antigen positron emission tomography/computed tomography (PSMA PET/CT) [1]. This report has led to widespread media attention [2]. Nuclear medicine physicians know well that PSMA ligands strongly accumulate in the salivary glands [3]. Although some researchers noticed that strong uptake of PSMA ligands was seen not only in the salivary glands but also in the dorsal wall of the nasopharynx [4], Valstar et al. investigated the TGs histologically and clinically in detail and named the gland TGs for the first time. They reported that irradiation of the TGs was associated with adverse 
effects, such as xerostomia and dysphagia. However, the physiological and clinical importance of the TGs has not yet been clarified [5].

The main physiological function of the salivary glands is to secrete saliva containing electrolytes, mucin, and proteins. Although uptake of PSMA ligands in the TGs seems to be useful for evaluating their existence or volume, the uptake is not appropriate to directly evaluate the secretory ability of the TGs, because PSMA ligands are not released from the salivary glands even after stimulation with vitamin C [6]. Therefore, the objective methods, other than PSMA PET/CT, that enable the evaluation of TG's secretory ability are warranted to clarify the pathophysiology of the diseases involving the TGs or to diagnose them.

99mTc-pertechnetate scintigraphy has been widely used for the clinical evaluation of the salivary gland

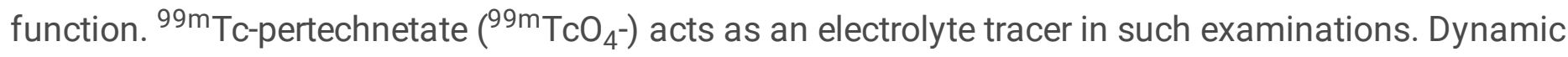
scans on anterior-posterior planar images have high time resolution, and the use of vitamin $\mathrm{C}$ stress test enables the evaluation of both accumulation in and secretion from the salivary glands $[7,8]$. However, since planar images are two-dimensional and provide little information on depth, it is impossible to distinguish the uptake in the TGs from that in the nasal mucus. For anatomical evaluation, single photon emission computed tomography/computed tomography (SPECT/CT) images provide superior data because fusion images of SPECT and CT provide three-dimensional anatomy. Therefore, SPECT/CT images are more suitable than planar images for evaluating the precise location of the TGs, which are small, thin, and predominantly overlaying the tori tubarius [1]. SPECT/CT scans are not routinely performed in salivary glands scintigraphy. However, evaluating thyroid tumors is a good indication of SPECT/CT scans with ${ }^{99 \mathrm{~m}}$ Tc-pertechnetate $[9,10]$. In our institution, the nasopharyngeal areas have been scanned in SPECT/CT with ${ }^{99 \mathrm{~m}} \mathrm{Tc}$-pertechnetate performed for the evaluation of thyroid tumors.

${ }^{18} \mathrm{~F}$-fluorodeoxyglucose $\left({ }^{18} \mathrm{~F}-\mathrm{FDG}\right)$ is not used to evaluate the salivary function because ${ }^{18} \mathrm{~F}$-FDG uptake in the salivary glands varies considerably among individuals. On the contrary, strong ${ }^{18} \mathrm{~F}$-FDG uptake in the tori tubarius is often observed and is considered to be physiological uptake derived from the tubal tonsils [11, 12]. Although the tubal tonsils are likely to exist beneath the TGs [13], it is unknown how much of the ${ }^{18} \mathrm{~F}$-FDG uptake in the tori tubarius is derived from the TGs or the tubal tonsils. ${ }^{11} \mathrm{C}$-methionine PET/CT has mainly been used to evaluate brain tumors [14]. ${ }^{11} \mathrm{C}$-methionine physiologically accumulates in the salivary glands [15], and its uptake may help to evaluate the function of the salivary glands [16]. ${ }^{11} \mathrm{C}$-methionine uptake in the salivary glands may reflect protein synthesis in the glands. However, it is unknown how much ${ }^{11} \mathrm{C}$-methionine physiologically accumulates in the TGs.

To clarify the physiological function of the TG, it is necessary to demonstrate whether ${ }^{99 \mathrm{~m}} \mathrm{Tc}$ pertechnetate uptake in the TGs is correlated with that in the other salivary glands, or whether ${ }^{18} \mathrm{~F}-\mathrm{FDG}$ and ${ }^{11} \mathrm{C}$-methionine uptakes in the TGs are correlated with that in the other salivary glands or palatine tonsils. The aim of this study was to retrospectively analyze the uptakes of ${ }^{99 \mathrm{~m}} \mathrm{Tc}$-pertechnetate, ${ }^{18} \mathrm{~F}-\mathrm{FDG}$, and ${ }^{11} \mathrm{C}$-methionine in the tori tubarius, other salivary glands, and palatine tonsils using ${ }^{99 \mathrm{~m}} \mathrm{Tc}-$ 
pertechnetate SPECT/CT, ${ }^{18} \mathrm{~F}-\mathrm{FDG} \mathrm{PET} / \mathrm{CT}$, and ${ }^{11} \mathrm{C}$-methionine PET/CT images, and to confirm whether these three imaging modalities are useful in evaluating TG function.

\section{Materials And Methods}

\section{Patients}

This retrospective study design was reviewed and approved by the Institutional Review Board of Saitama Medical University International Medical Center, and the need for written informed consent was waived. We enrolled the patients who underwent ${ }^{99 \mathrm{~m} T c-p e r t e c h n e t a t e ~ s c i n t i g r a p h y ~ i n c l u d i n g ~ S P E C T / C T ~ o f ~ t h e ~}$ head and neck from January 2009 to October 2020 and the patients who underwent both ${ }^{11} \mathrm{C}$-methionine PET/CT and ${ }^{18}$ F-FDG PET/CT within one month of each other PET/CT scan from January 2008 to December 2016. Patients with a history of Sjogren syndrome, those who had undergone chemotherapy for any malignancy, and those who underwent radiation therapy for malignancy of the head and neck were excluded from the analysis. Furthermore, patients whose imaging quality of FDG PET/CT was inappropriate due to extravasation of ${ }^{18} \mathrm{~F}-\mathrm{FDG}$ and fasting failure before FDG PET/CT scanning were also excluded.

\section{Imaging Protocols}

For ${ }^{99 \mathrm{~m} T c-p e r t e c h n e t a t e ~ S P E C T / C T}$, the patients were intravenously administered with $185 \mathrm{MBq}$ of ${ }^{99 \mathrm{~m}} \mathrm{Tc}-$ pertechnetate solution, which was obtained from a commercial ${ }^{99} \mathrm{Mo}-{ }^{99} \mathrm{~m} T c$ generator (Ultra-Techne Kow, FUJIFILM Toyama Chemical Co., Ltd., Tokyo, Japan). Prior to imaging, the patients gargled with water to eliminate ${ }^{99 \mathrm{~m}}$ Tc-pertechnetate in the salivary juice of the oral cavity. Planar images and SPECT/CT images were acquired $10 \mathrm{~min}$ and $30 \mathrm{~min}$ after the injection, respectively. For imaging, we used an integrated SPECT/CT scanner (Symbia Intevo, Siemens, Erlangen, Germany) during 2015-2020 and another SPECT/CT scanner (Symbia T6, Siemens, Erlangen, Germany) during 2009-2014. Both scanners had two detector heads fitted with low-energy, high-resolution collimators. Acquisition of anterior and posterior head-to-chest planar images was followed by SPECT/CT. The SPECT portion of Symbia Intevo was acquired using the following parameters: energy peak, $140 \mathrm{keV}$ with $15 \%$ width; acquisition, continuous rotation mode of $180^{\circ}$ for each head; projection, a total of 60 over $360^{\circ}$ with a dwell time of $20 \mathrm{~s} / \mathrm{view}$; reconstruction, ordered subset conjugate gradient minimizer (OSCGM) algorithm with one subset and 48 iterations; voxel size, $2.54 \times 2.54 \times 2.54 \mathrm{~mm}$; and matrix, $256 \times 256$. The SPECT portion of Symbia T6 was acquired using the following parameters: energy peak, $140 \mathrm{keV}$ with $15 \%$ width; acquisition, continuous rotation mode of $180^{\circ}$ for each head; projection, a total of 48 over $360^{\circ}$ with a dwell time of $5 \mathrm{~s} /$ view; reconstruction, three-dimensional ordered subset expectation maximization (3DOSEM) algorithm with four subsets and six iterations; voxel size, $4.80 \times 4.80 \times 4.80 \mathrm{~mm}$; and matrix, 128 $\times 128$. The area that was scanned with SPECT was also scanned using CT with the following parameters: tube voltage, $130 \mathrm{kV}$; tube current determined by automatic dose modulation; and matrix, $512 \times 512$. 
Before undergoing ${ }^{11} \mathrm{C}$-methionine PET/CT, the patients fasted for at least $4 \mathrm{~h}$. The patients were intravenously administered with $6.0 \mathrm{MBq} / \mathrm{kg}$ of ${ }^{11} \mathrm{C}$-methionine solution, which was synthesized on site. The dose of syringes before and after ${ }^{11} \mathrm{C}$-methionine injection was counted, and the injection dose was calculated. PET/CT images were acquired $15 \mathrm{~min}$ after ${ }^{11} \mathrm{C}$-methionine injection using a PET/CT system combined with a 6- or 16-slice CT scanner (Biograph 6 or Biograph 16, Siemens, Erlangen, Germany). After brain scanning for $7 \mathrm{~min}$, body scanning from the thigh level to the skull base was performed in 1.5 min per bed position. Images were reconstructed in a $168 \times 168$ matrix with $3.0 \times 3.0 \times 5.0 \mathrm{~mm}$ voxel size using two-dimensional ordered subset expectation maximization (2D-OSEM) with iteration 3 and subset 8 with a Gaussian filter of 6-mm full width at half maximum. The attenuation correction was performed using transmission CT with the following parameters: matrix, $512 \times 512$; slice thickness, $5 \mathrm{~mm}$; tube voltage $120 \mathrm{keV}$; automated tube current modulation (CARD Dose4D, quality reference of $50 \mathrm{mAs}$ ); tube rotation, $0.5 \mathrm{~s}$; table speed, $10 \mathrm{~mm} /$ rotation; and pitch of 1.0 .

${ }^{18} \mathrm{~F}-\mathrm{FDG}$ PET/CT was performed within one month of ${ }^{11} \mathrm{C}$-methionine PET/CT. The patients fasted for at least $6 \mathrm{~h}$ before the test. Blood glucose levels were measured in all patients before ${ }^{18} \mathrm{~F}$-FDG administration; no patient had blood glucose levels exceeding $200 \mathrm{mg} / \mathrm{dL}$ underwent this test. The patients were intravenously administered with 3.7-4.0 MBq/kg of ${ }^{18} \mathrm{~F}-\mathrm{FDG}$ solution, which was synthesized on site. PET/CT images were acquired $60 \mathrm{~min}$ after the injection. After brain scanning for 7 min, body scanning from the thigh level to the skull base was performed in $2 \mathrm{~min}$ per bed position. The other PET/CT imaging and reconstruction protocols were identical to those of ${ }^{11} \mathrm{C}$-methionine PET/CT.

\section{Image Analysis}

${ }^{99 m}$ Tc-pertechnetate SPECT/CT images were retrospectively reviewed using visual and quantitative methods. Because the TGs are predominantly overlaying the tori tubarius [1], we measured the uptake of the TGs by drawing volumes of interest (VOIs) on the tori tubarius. The three types of images (SPECT, CT, and the fusion images) were visually reviewed to determine whether the uptake in the tori tubarius was higher than that in the background. For quantitative analysis, maximal counts of the tori tubarius, parotid salivary glands (PSGs), submandibular salivary glands (SmSGs), and sublingual salivary glands (SISGs) were measured by drawing VOls over SPECT/CT fusion images. As a reference, the mean and maximal counts of the posterior neck muscles were also measured using VOls. The counts of the palatine tonsils were unable to be measured because the counts of the oral cavity were extremely high. The maximal counts of the tori tubarius, PSGs, SmSGs, SISGs and the background were divided by the mean counts of the background, and the five ratios were used for comparative analysis.

While reviewing the PET/CT images, the maximal radioactivity of ${ }^{18} \mathrm{~F}-\mathrm{FDG}$ and ${ }^{11} \mathrm{C}$-methionine in the tori tubarius, PSGs, SmSGs, SISGs and palatine tonsils was measured by drawing VOls over PET/CT fusion images. The measured radioactivity was expressed as the maximum standardized uptake value (SUVmax). The SUV normalizes the measured tissue radioactivity in a VOI by the injected dose and body 
weight, and itis calculated according to the following formula: SUV= radioactivity concentration in VOI $(\mathrm{MBq} / \mathrm{mL}) /$ injection dose (MBq/kg body weight).

\section{Statistical Analysis}

Quantitative data are expressed as the mean \pm SD values. In ${ }^{99 m}$ Tc-pertechnetate SPECT/CT analysis, the ratios of the maximal counts of the tori tubarius, three major salivary glands and background to the mean counts of the background were analyzed using one-way analysis of variance (ANOVA) with Dunnett's multiple comparisons test. In PET/CT analysis, the correlation of SUVmax between the tori tubarius and the other glands was analyzed using Pearson's correlation analysis. All statistical tests were two-tailed, and $p$-values $<0.05$ were considered statistically significant. Statistical analyses were conducted using GraphPad Prism 9.0 (GraphPad Software, Inc., San Diego, CA, USA).

\section{Results}

\section{Patient characteristics}

Twelve Japanese patients underwent ${ }^{99 \mathrm{~m}} \mathrm{Tc}$-pertechnetate SPECT/CT from January 2009 to October 2020 , and data of all these patients were included in the evaluation. The median age was 62 years (range, 46 - 70 years), and the male-to-female ratio was 9:3.

A total of 218 patients who underwent ${ }^{11} \mathrm{C}$-methionine PET/CT and ${ }^{18} \mathrm{~F}$-FDG PET/CT were enrolled. Among them, 85 patients were excluded due to the history of Sjogren syndrome, radiation therapy, and chemotherapy. In addition, three patients were excluded due to extravasation of ${ }^{18} \mathrm{~F}$-FDG (two patients) and failure to fast before ${ }^{18}$ F-FDG PET scan (one patient). Finally, data of 130 patients were analyzed. The median age was 55 years (range, 0.8 - 83 years), and the male-to-female ratio was 78:52.

\section{9mTc-pertechnetate SPECT findings}

Visual analysis showed no significant ${ }^{99 \mathrm{~m}} \mathrm{Tc}$-pertechnetate uptake in the tori tubarius in any of 12 patients (Fig. 1). In the quantitative analysis, the maximal count ratios in the tori tubarius $(2.6 \pm 1.5)$ and SISGs $(2.6 \pm 1.5)$ were not significantly higher than those in the background $(2.1 \pm 1.0, p=0.38)$, while the maximal count ratios in the PSGs $(28.4 \pm 11.6)$ and SmSGs $(21.4 \pm 11.4)$ were significantly higher than that in the background $(p<0.001)$ (Fig. 2).

\section{PET/CT findings of ${ }^{18} \mathrm{~F}-\mathrm{FDG}$ and ${ }^{11} \mathrm{C}$-methionine}

The interval between ${ }^{18} \mathrm{~F}$-FDG PET/CT and ${ }^{11} \mathrm{C}$-methionine PET/CT was $6.0 \pm 7.0$ days. Figure 3 shows representative ${ }^{18} \mathrm{~F}-\mathrm{FDG}$ and ${ }^{11} \mathrm{C}$-methionine PET/CT images of a patient's tori tubarius, each salivary gland, and palatine tonsils. Figure 4 summarizes the results of the uptake correlations between the tori tubarius and the other glands. Both ${ }^{18} \mathrm{~F}-\mathrm{FDG}$ and ${ }^{11} \mathrm{C}$-methionine uptakes in the tori tubarius were positively correlated with that in the palatine tonsils $(r=0.56, p<0.0001 ; r=0.48, p<0.0001$, 
respectively). On the contrary, ${ }^{18} \mathrm{~F}-\mathrm{FDG}$ uptake in the tori tubarius was not positively correlated with that in the PSGs, SmSGs, and SISGs $\left(r=-0.19, p=0.03 ; r=-0.02, p=0.81 ; r=0.12, p=0.17\right.$, respectively). ${ }^{11} \mathrm{C}$ methionine uptake in the tori tubarius was positively correlated with that in the SmSGs and SISGs ( $r=$ $0.24, p=0.01 ; r=0.32, p<0.01$, respectively). However, ${ }^{11} \mathrm{C}$-methionine uptake in the tori tubarius did not correlate with that in the PSGs $(r=0.16, p=0.08)$.

\section{Discussion}

This study demonstrated that the TGs were invisible on ${ }^{99 m}$ Tc-pertechnetate SPECT/CT images, and that ${ }^{18} \mathrm{~F}$-FDG and ${ }^{11} \mathrm{C}$-methionine uptakes in the TGs were not undistinguishable from the uptake in the tubal tonsils. To our knowledge, this is the first report evaluating the uptake of radiopharmaceuticals in the TGs other than PSMA ligands.

Our results imply that the TGs were not found until PSMA PET emerged. We did not miss the TGs but had been unable to observe them on ${ }^{99 \mathrm{~m}} \mathrm{Tc}$-pertechnetate images. In addition, we had believed without doubt that ${ }^{18} \mathrm{~F}$-FDG and ${ }^{11} \mathrm{C}$-methionine uptakes in the tori tubarius were derived only from the tubal tonsils. If 99mTc-pertechnetate SPECT/CT can help visualize the uptake in the TGs and if the secretion from the TGs is controlled by taste stimulation in the oral cavity, it might have been possible to evaluate their secretory function using the vitamin $\mathrm{C}$ stress test. Salivary gland scintigraphy reveals the salivary gland function of both uptake and secretion, and the secretory function can be measured with the vitamin C stress test, which is often used for evaluation of Sjogren syndrome [7, 8]. However, our results suggested that it is not possible to use the stress to evaluate the secretory function of the TGs because the uptake in the TGs itself was not observed. Some reasons behind this invisibility of the TGs on ${ }^{99 \mathrm{~m}} \mathrm{Tc}$-pertechnetate SPECT/CT images are as follows. First, the TGs may express few $\mathrm{Na}+/ \mathrm{K}+/ 2 \mathrm{Cl}$ - cotransporters (NKCCls), via which ${ }^{99 \mathrm{~m}} \mathrm{Tc}$-pertechnetate rapidly accumulates in the PSGs and SSGs as substitute for $\mathrm{Cl}$ - [17]. ${ }^{99 m}$ Tc-petechnetate imaging does not visualize the sublingual salivary glands [18], whose histological feature is similar to the TGs in that the main type of these glands is mucous type [19]. Therefore, if the invisibility of the sublingual salivary gland on ${ }^{99 \mathrm{~m}} \mathrm{Tc}$-pertechnetate imaging is caused by modest expression of NKCCls, the TGs may also be invisible on images. Second, the spatial resolution of SPECT images may be too low to visualize the TGs. The TGs are thin structures localized on the posterior wall of the nasopharynx [1]. PET has a higher spatial resolution than does SPECT, and PSMA PET/CT can help visualize thin and small tissues such as the TGs. However, PSMA ligands are not released from the salivary glands even with vitamin $C$ stimulation [6]. Therefore, the secretory function cannot be evaluated with PSMA PET/CT. ${ }^{18} \mathrm{~F}$-tetrafluoroborate $\left({ }^{18} \mathrm{~F}\right.$-TFB $)$, a sodium/iodine symporter-target PET tracer, has already been used for PET/CT imaging in healthy humans [20]. ${ }^{18} \mathrm{~F}-\mathrm{FTB}$ strongly accumulates in the salivary glands as well as in the thyroid glands [21]. If ${ }^{18} \mathrm{~F}-\mathrm{TFB}$ is secreted from the major salivary glands, the secretory function of the TGs might also be evaluated using ${ }^{18} \mathrm{~F}$-TFB PET. 
${ }^{18} \mathrm{~F}-\mathrm{FDG}$ uptake in the tori tubarius was correlated with that in the palatine tonsils but not with that in the other salivary glands. Although ${ }^{11} \mathrm{C}$-methionine uptake in the tori tubarius was mildly correlated with that in the SmSGs and SISGs, the correlation was weaker than that between the tori tubarius and the palatine tonsils. These two radiopharmaceuticals are metabolic tracers, and their uptake is not specific to the gland tissues. In particular, the tubal tonsils coexist with the TGs in the tori tubarius, and our results indicated that the uptake of ${ }^{18} \mathrm{~F}-\mathrm{FDG}$ and ${ }^{11} \mathrm{C}$-methionine in the tori tubarius is strongly affected by the tubal tonsils. Before the discovery of the TGs using PSMA PET/CT by Valstar et al., most of the nuclear medicine physicians must have considered that ${ }^{18} \mathrm{~F}-\mathrm{FDG}$ uptake in the tori tubarius is derived only from the tubal tonsils. This is because ${ }^{18} \mathrm{~F}-\mathrm{FDG}$ uptake in the pharyngeal, tubal, palatine, and lingual tonsils, called the Waldeyer ring, often changes in tandem with each other tonsils. Considering that ${ }^{18} \mathrm{~F}-\mathrm{FDG}$ and ${ }^{11} \mathrm{C}$-methionine uptakes in the tori tubarius were positively correlated with that in the palatine tonsil, the uptake of both tracers in the tori tubarius is mainly affected by the tubal tonsils and not by the TGs. Therefore, ${ }^{18} \mathrm{~F}-\mathrm{FDG}$ and ${ }^{11} \mathrm{C}$-methionine uptakes in the tori tubarius cannot be used to evaluate the physiological functions of the TGs. On the contrary, ${ }^{11} \mathrm{C}$-methionine uptake in the tori tubarius was mildly correlated with that in the SmSGs and SISGs, which suggests that the characteristics of the TGs may be similar to the latter two glands. PSMA ligands specifically accumulate in the salivary glands, and there is no evidence that PSMA ligands accumulate in the tonsils. Therefore, the combinational analysis of PSMA ligands and ${ }^{11} \mathrm{C}$-methionine may be useful to separately assess the glandular tissues and tonsillar tissues.

The definition and nomenclature of the TGs are still debatable [22]. Although Valstar et al. categorized the glands into the salivary glands, the TGs may rather belong to the airway than to the digestive tract. The TGs are located in the nasopharyngeal area where swallowed food does not pass but air from the nose does. Furthermore, Valstar et al. reported that TGs do not produce amylase, an enzyme that degrades of carbohydrates, but produce mucin, which may prevent drying of the nasopharynx. We consider that the entity of the TGs may be closer to "the nasal glands" than the salivary glands, and they may be able to be expressed as "the major nasal glands". In fact, PSMA ligands accumulate in the minor glands of the nasal cavity [4], which may be called "the minor nasal glands". Discussion by otolaryngologists and anatomists should be needed to determine the definition or nomenclature of TSs.

The limitation of this study is the lack of a direct comparison of the findings of the three image modalities with those of PSMA PET/CT images. There are no data on PSMA uptake in the TGs in the Japanese population, and the racial differences in parameters such as the size of the TGs were not

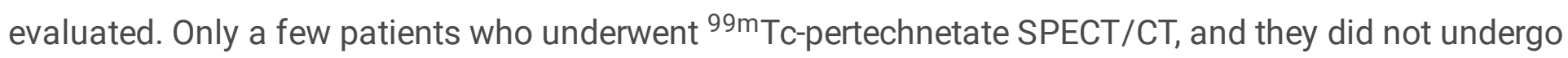
either ${ }^{11} \mathrm{C}$-methionine or ${ }^{18} \mathrm{~F}$-FDG PET/CT.

\section{Conclusions}

We demonstrated that ${ }^{99 \mathrm{~m}} \mathrm{Tc}$-pertechnetate SPECT/CT images did not show significant uptake in the TGs. ${ }^{18} \mathrm{~F}-\mathrm{FDG}$ and ${ }^{11} \mathrm{C}$-methionine uptakes in the tori tubarius were correlated with that in the palatine 
tonsils, which suggests that the uptake in the tori tubarius is likely to be affected by that in the tubal

tonsils. On the contrary, ${ }^{18} \mathrm{~F}$-FDG and ${ }^{11} \mathrm{C}$-methionine uptakes in the tori tubarius were little related to that in the other salivary glands. It seems difficult to clarify the physiological function (seromucous fluidsecreting ability) of the TGs using ${ }^{99 \mathrm{~m}} \mathrm{Tc}$-pertechnetate SPECT/CT, ${ }^{18} \mathrm{~F}-\mathrm{FDG}$, and ${ }^{11} \mathrm{C}$-methionine PET/CT imaging.

\section{Declarations}

\section{Acknowledgements}

We thank all the staff in the Department of Nuclear Medicine at Saitama Medical University International Medical Center for setting the environment of clinical practice and research. We would like to thank Editage (www.editage.com) for English language editing.

\section{Funding}

No specific funding was received.

\section{Authors' information}

\section{Affiliations}

1. Department of Nuclear Medicine, Saitama Medical University International Medical Center, 1397-1 Yamane, Hidaka, Saitama, 350-1298, Japan.

2. Division of Nuclear Medicine, Department of Radiology, Saitama Medical University Hospital, 38 Moro-Hongo, Moroyama, 350-0495, Japan.

Yohji Matsusaka ${ }^{1}$; Tomohiko Yamane ${ }^{1}$; Kenji Fukushima ${ }^{1}$; Akira Seto ${ }^{1}$; Ichiro Matsunari ${ }^{2}$; Ichiei Kuji ${ }^{1}$.

\section{Authors' contributions}

YM contributed to the study design, preparation of the study, conducting measurements, data analysis, and drafting of the manuscript. TY, KF and AS contributed to the study design, preparation of the study, data analysis, and critical revision of the manuscript. IM and IK contributed to the study design and critical revision of the manuscript. All authors read and approved the final manuscript.

\section{Corresponding author}

Correspondence to Yohji Matsusaka.

\section{Ethics declarations}

This retrospective study design was reviewed and approved by the Institutional Review Board of Saitama Medical University International Medical Center, and the need for written informed consent was waived. 


\section{Conflict of interests}

The authors declare that they have no conflicts of interest.

\section{References}

1. Valstar MH, de Bakker BS, Steenbakkers R, de Jong KH, Smit LA, Klein Nulent TJW, et al. The tubarial salivary glands: A potential new organ at risk for radiotherapy. Radiother Oncol. 2020. doi:10.1016/j.radonc.2020.09.034.

2. Mudry A, Jackler RK. Are "tubarial salivary glands" a previously unknown structure? Radiother Oncol. 2020. doi:10.1016/j.radonc.2020.12.003.

3. Afshar-Oromieh A, Malcher A, Eder M, Eisenhut M, Linhart HG, Hadaschik BA, et al. PET imaging with a $\left[{ }^{68} \mathrm{Ga}\right]$ gallium-labelled PSMA ligand for the diagnosis of prostate cancer: biodistribution in humans and first evaluation of tumour lesions. Eur J Nucl Med Mol Imaging. 2013;40:486-95. doi:10.1007/s00259-012-2298-2.

4. Klein Nulent TJW, Valstar MH, de Keizer B, Willems SM, Smit LA, Al-Mamgani A, et al. Physiologic distribution of PSMA-ligand in salivary glands and seromucous glands of the head and neck on PET/CT. Oral Surgery, Oral Medicine, Oral Pathology and Oral Radiology. 2018;125:478-86. doi:https://doi.org/10.1016/j.0000.2018.01.011.

5. Suvvari T, Arigapudi N. The tubarial glands: Discovered but not defined - A narrative review. Journal of Radiation Cancer Research. 2020;11:140-1. doi:10.4103/jrcr.jrcr_57_20.

6. Afshar-Oromieh A, Avtzi E, Giesel FL, Holland-Letz T, Linhart HG, Eder M, et al. The diagnostic value of $\mathrm{PET} / \mathrm{CT}$ imaging with the ${ }^{68} \mathrm{Ga}$-labelled PSMA ligand HBED-CC in the diagnosis of recurrent prostate cancer. Eur J Nucl Med Mol Imaging. 2015;42:197-209. doi:10.1007/s00259-014-2949-6.

7. Aung W, Murata Y, Ishida R, Takahashi Y, Okada N, Shibuya H. Study of quantitative oral radioactivity in salivary gland scintigraphy and determination of the clinical stage of Sjogren's syndrome. $\mathrm{J} \mathrm{Nucl}$ Med. 2001;42:38-43.

8. Tensing EK, Nordstrom DC, Solovieva S, Schauman KO, Sippo-Tujunen I, Helve T, et al. Salivary gland scintigraphy in Sjogren's syndrome and patients with sicca symptoms but without Sjogren's syndrome: the psychological profiles and predictors for salivary gland dysfunction. Ann Rheum Dis. 2003;62:964-8.

9. Lee R, So Y, Song YS, Lee WW. Evaluation of Hot Nodules of Thyroid Gland Using Tc-99m Pertechnetate: a Novel Approach Using Quantitative Single-Photon Emission Computed Tomography/Computed Tomography. Nucl Med Mol Imaging. 2018;52:468-72. doi:10.1007/s13139-018-0554-5.

10. Chantadisai M, Kingpetch K. Usefulness of ${ }^{99 \mathrm{~m}} \mathrm{Tc}$-pertechnetate whole body scan with neck and chest SPECT/CT for detection of post-surgical thyroid remnant and metastasis in differentiated thyroid cancer patients. Ann Nucl Med. 2014;28:674-82. doi:10.1007/s12149-014-0864-3. 
11. Lee HS, Kim JS, Roh J-L, Choi S-H, Nam SY, Kim SY. Clinical values for abnormal ${ }^{18}$ F-FDG uptake in the head and neck region of patients with head and neck squamous cell carcinoma. Eur J Radiol. 2014;83:1455-60. doi:https://doi.org/10.1016/j.ejrad.2014.05.020.

12. Chen Y-K, Su C-T, Chi K-H, Cheng R-H, Wang S-C, Hsu C-H. Utility of ${ }^{18} \mathrm{~F}-\mathrm{FDG}$ PET/CT Uptake Patterns in Waldeyer's Ring for Differentiating Benign from Malignant Lesions in Lateral Pharyngeal Recess of Nasopharynx. J Nucl Med. 2007;48:8-14.

13. Truong MT, Koltai PJ. Current Techniques of Adenoidectomy. In: Sleep Apnea and Snoring E-Book: Surgical and Non-Surgical Therapy. 1999.

14. Yamane T, Sakamoto S, Senda M. Clinical impact of ${ }^{11} \mathrm{C}$-methionine PET on expected management of patients with brain neoplasm. Eur J Nucl Med Mol Imaging. 2010;37:685-90. doi:10.1007/s00259-009-1302-y.

15. Harris SM, Davis JC, Snyder SE, Butch ER, Vavere AL, Kocak M, et al. Evaluation of the biodistribution of ${ }^{11} \mathrm{C}$-methionine in children and young adults. J Nucl Med. 2013;54:1902-8. doi:10.2967/jnumed.112.118125.

16. Buus S, Grau C, Munk OL, Bender D, Jensen K, Keiding S. ${ }^{11}$ C-methionine PET, a novel method for measuring regional salivary gland function after radiotherapy of head and neck cancer. Radiother Oncol. 2004;73:289-96. doi:10.1016/j.radonc.2004.09.009.

17. Helman J, Turner RJ, Fox PC, Baum BJ. ${ }^{99 \mathrm{~m}}$ Tc-pertechnetate uptake in parotid acinar cells by the $\mathrm{Na}+/ \mathrm{K}+/ \mathrm{Cl}$ - co-transport system. J Clin Invest. 1987;79:1310-3. doi:10.1172/JCl112954.

18. Zhao Y, Xia Y, Liu H, Wang Z, Chen Y, Zhang W. Potential Applications of ${ }^{68}$ Ga-PSMA-11 PET/CT in the Evaluation of Salivary Gland Uptake Function: Preliminary Observations and Comparison with ${ }^{99} \mathrm{~m}_{\mathrm{TCO}_{4}}$ - Salivary Gland Scintigraphy. Contrast Media Mol Imaging. 2020;2020:1097516. doi:10.1155/2020/1097516.

19. Varga G. Physiology of the salivary glands. Surgery (Oxford). 2012;30:578-83. doi:https://doi.org/10.1016/j.mpsur.2012.09.010.

20. Jiang H, DeGrado TR. $\left[{ }^{18} \mathrm{~F}\right]$ Tetrafluoroborate $\left(\left[{ }^{18} \mathrm{~F}\right] \mathrm{TFB}\right)$ and its analogs for PET imaging of the sodium/iodide symporter. Theranostics. 2018;8:3918-31. doi:10.7150/thno.24997.

21. Jiang H, Schmit NR, Koenen AR, Bansal A, Pandey MK, Glynn RB, et al. Safety, pharmacokinetics, metabolism and radiation dosimetry of ${ }^{18} \mathrm{~F}$-tetrafluoroborate $\left({ }^{18} \mathrm{~F}-\mathrm{TFB}\right)$ in healthy human subjects. EJNMMI Res. 2017;7:90. doi:10.1186/s13550-017-0337-5.

22. Bikker FJ, Vissink A. Letter to the editor concerning Valstar et al., [Radiother Oncol 2020 Sep 23;S0167-8140(20)30809-4. doi: 10.1016/j.radonc.2020.09.034]. Radiother Oncol. 2020. doi:10.1016/j.radonc.2020.12.005.

\section{Figures}



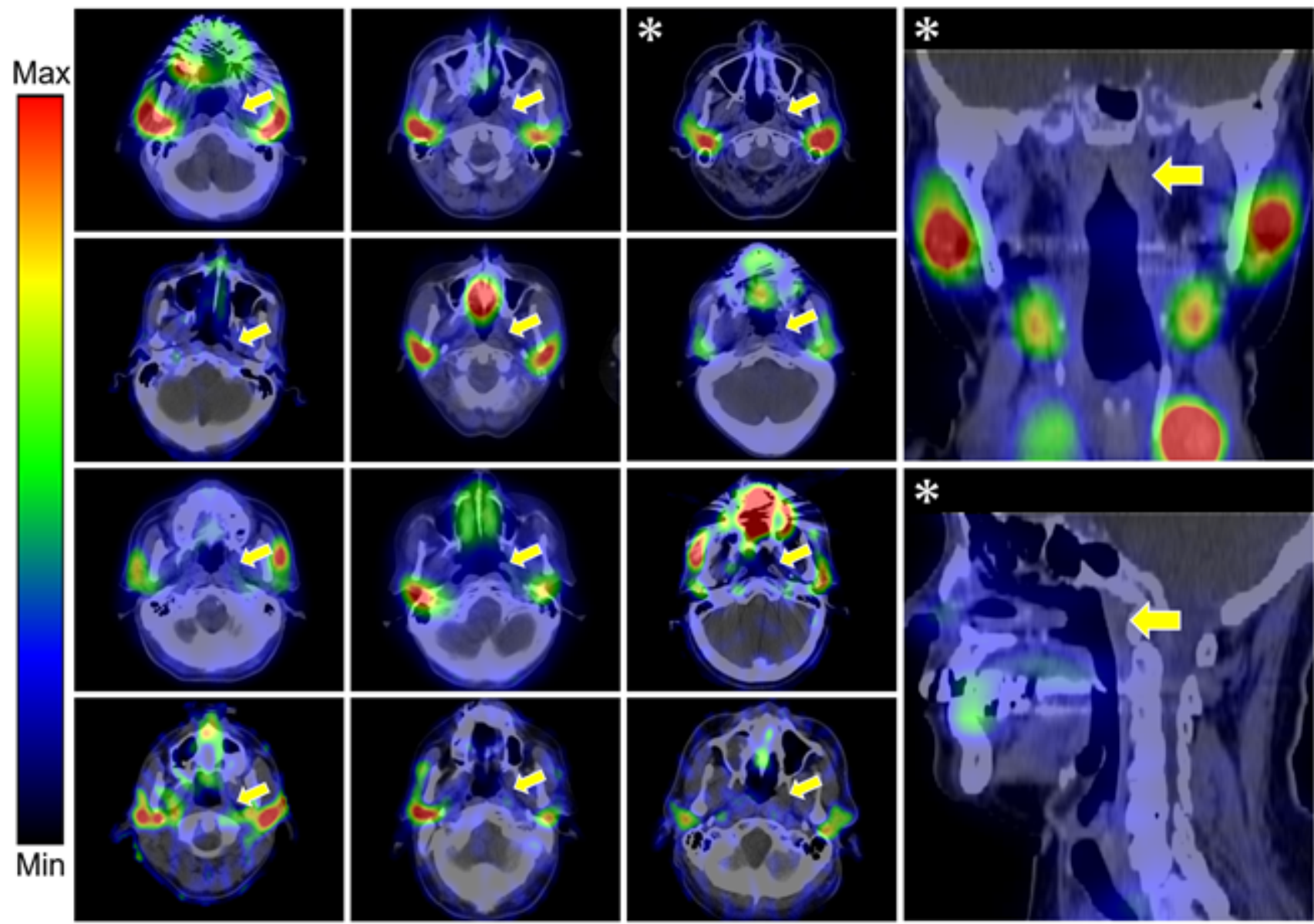

\section{Figure 1}

99mTc-pertechnetate SPECT/CT images of all the patients. Yellow arrows show the torus tubarius. Images marked with asterisks belong to the same patient. 
ns

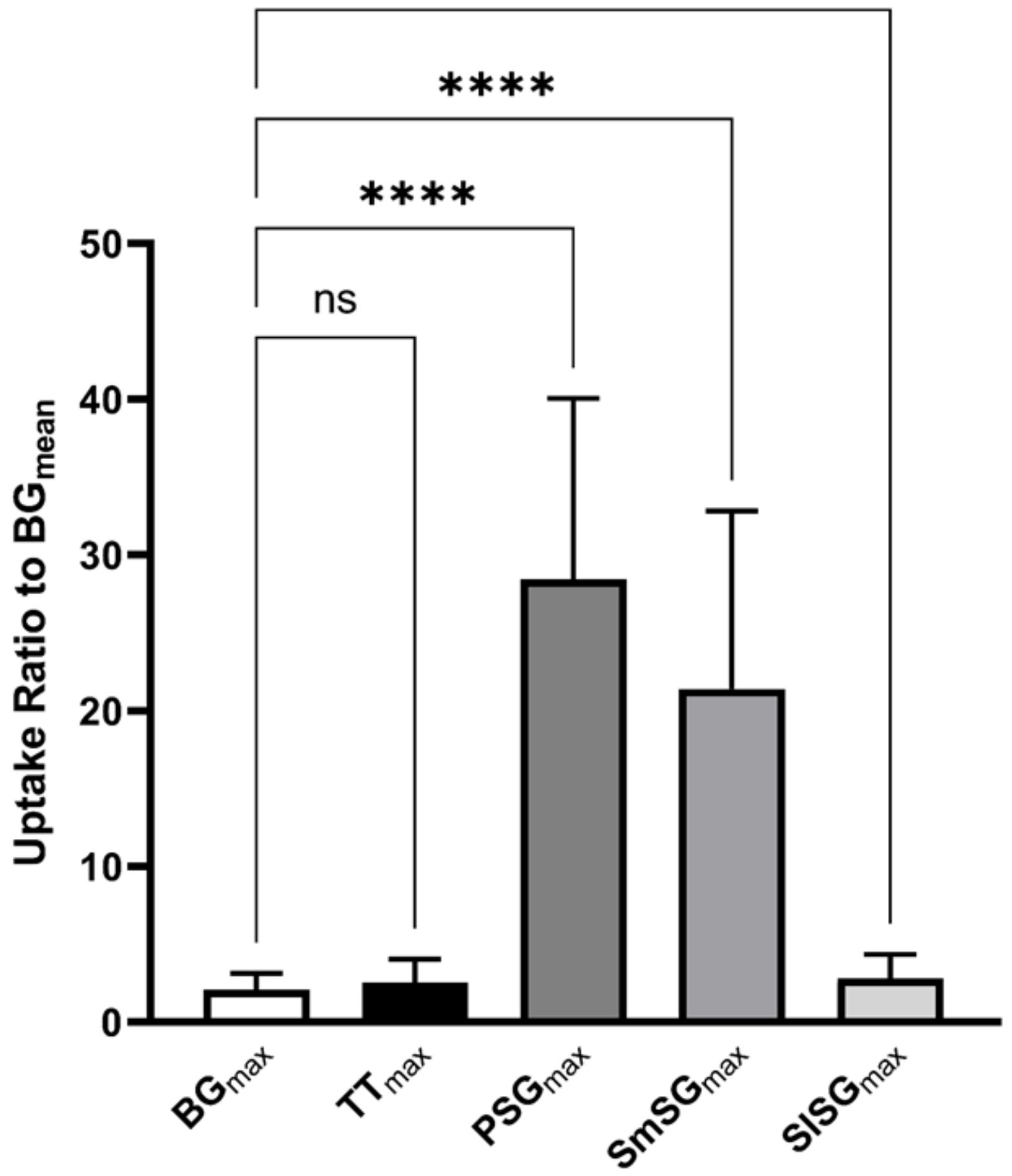

Figure 2

Ratios of maximal counts of 99mTc-pertechnetate in each salivary gland and the background to mean counts of the background. BG, background; TT, torus tubarius; PSG, parotid salivary gland; SmSG, submandibular salivary gland; $n s$, not significant; ${ }^{\star \star \star \star} p<0.0001$. 


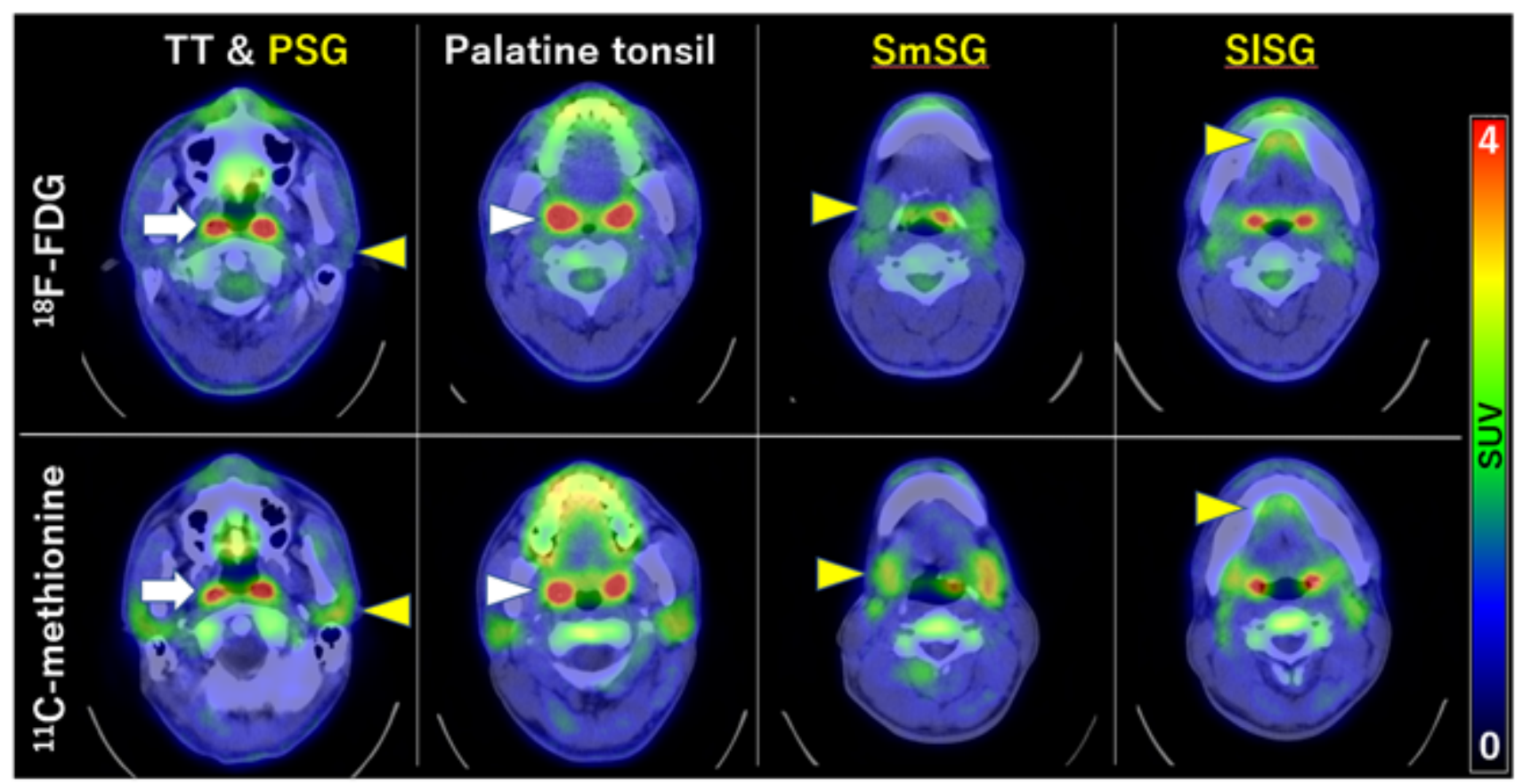

Figure 3

Representative PET/CT images of a 37-year-old male patient. Upper row, 18F-FDG PET/CT images; lower row, 11C-methionine PET/CT images. TT (tori tubarius, white arrows), Palatine tonsil (white arrowhead), PSG (parotid salivary gland, yellow arrowheads), SmSG, (submandibular salivary gland, yellow arrowheads), and SISG (sublingual salivary gland, yellow arrowheads).
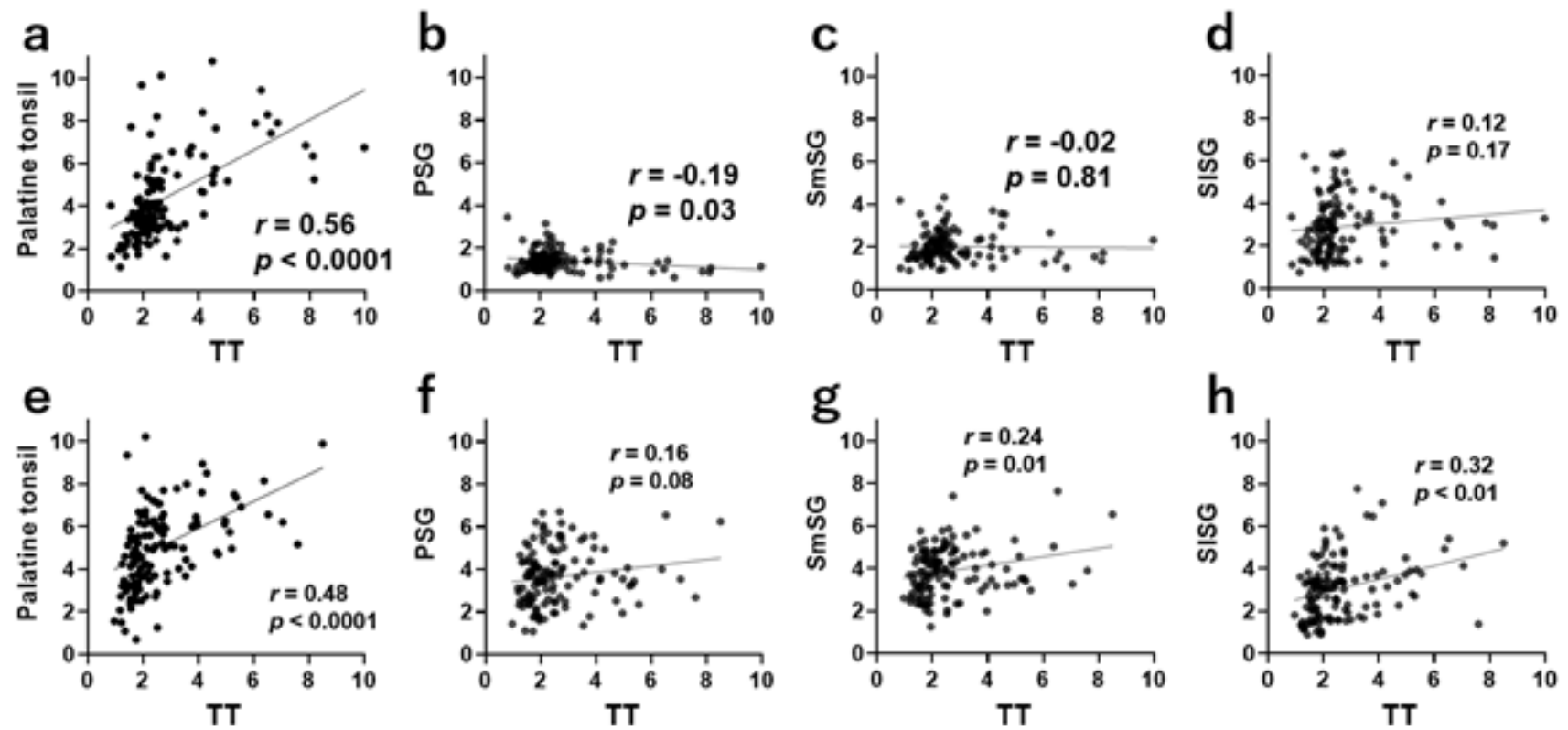

\section{Figure 4}

Correlations of SUVmax in the tori tubarius (TT) with that in the palatine tonsil and the other major salivary glands (a-d, 18F-FDG; e-h, 11C-methionine). PSG, parotid salivary gland; SmSG, submandibular salivary gland; SISG, sublingual salivary gland. 